\title{
Decentralised Centralism: Insights From A Malaysian Cluster School of Excellence
}

\author{
Huan Yik Lee \\ University of Queensland \\ Moses Samuel ${ }^{\mathrm{a}}$ \\ Taylor's University
}

\begin{abstract}
Currently, in many developing countries, there have been intensified efforts by policymakers to push for decentralisation of education as part of a neo-liberal reform agenda to improve school management efficiency and cater to localised needs. In the Malaysian context, the government has attempted further decentralisation of autonomy in selected public schools, marking a shift from the post-independence centralised education structure. This has led to the development of Cluster Schools of Excellence, practising some form of school-based management and accorded autonomy in the selection of niche areas, programme planning and programme implementation. Drawing primarily on the interview narratives from school administrators as key policy actors, this study examines how autonomy is manifested at the micro-level and how the school administrators exercise their agency when they are accorded autonomy. Using a decentralised centralism framework, the tensions and complexities in education policy implementation are highlighted in this study. Findings reveal that agency and autonomy are held by both macro and micro-level policy actors in varying degrees, and that school administrators have fundamental agency in school-level policy implementation. The study also explores the dynamics of the decentralisation process and raises the issue of re-centralisation of authority through decentralisation of education.
\end{abstract}

Keywords: Malaysia, decentralisation, autonomy, agency, educational policy

\section{Introduction}

Over the past two decades, policymakers have intensified the push for decentralisation of education as a part of neo-liberal reform initiatives in many developing countries, for instance, in Chile (Parry, 1997), El Salvador (Cuéllar-Marchelli, 2003), Ghana (Chapman et al., 2002), Kenya (M’Nkanata, 2012), Malawi and Zimbabwe (Chikoko, 2009), China (Cheng, 1994), Thailand (Gamage \& Sooksomchitra, 2004), Nepal (Khanal, 2010) and Indonesia (Bandur, 2012). The United Nations' Sustainable Development Goals advocates improvement in education quality (Niño-Zarazúa, 2016; United Nations, 2015) and in this context, education decentralisation is often adopted as a governance strategy (Ball, 2012; Lefebvre \& Thomas, 2017) to improve school management efficiency and cater to localised needs. According to Bjork (2006), decentralisation can reduce administrative bottlenecks in decision-making, increase the efficiency of government and its responsiveness to local needs, enhance the accountability of public institutions, improve service delivery, and allow greater political representation and participation of diverse groups in decision making. In recent years, governments in several developing countries, including Malaysia (World Bank, 2013; Tan, 2012) have given serious consideration to decentralisation of education. This paper aims to highlight the issue of decentralisation of authority for decision making within the education system in Malaysia. In particular, it is a case study of a 'Cluster School of Excellence' initiative in Malaysia as one possible model of decentralisation.

a Correspondence can be directed to: moses.samuel@taylors.edu.my 


\section{Decentralisation of Education in Malaysia: Cluster Schools of Excellence}

Studies conducted by the World Bank (2013) reported that the high level of centralisation in the Malaysian education system had, to a certain extent, stifled efficient production and distribution of education services over the years. In this regard, the Malaysian government has recently implemented various measures, aimed at shifting more autonomy towards the schools at the grassroots level, and slowly moving away from the centralised education structure.

In Malaysia, the 'Cluster School of Excellence' (hereafter, CSE) is a form of decentralisation of education, which has been implemented since 2007 (Mohd Noor \& Crossley, 2013). CSE was established by the Malaysian Ministry of Education (hereafter, MOE) to decentralise power to schools in order to develop their 'full potential within their cluster of excellence' under Chapter Nine of the Education Development Master Plan 2006-2010 (MOE, 2006). These schools are clustered based on their excellence in certain niche areas. Each CSE has been given two choices for its niche areas. One of those niche areas must be academic, while the other is sports or extra-curricular activities. Examples of the niche areas may include English language and robotics or Mathematics and debates. Generally, students enrolled in CSE will gain more exposure and experience, especially in the schools' niche areas. However, the school curriculum and examinations are still based on centralised structures, like that of other non-cluster schools.

Here, CSE in Malaysia differs from the common understanding of cluster schools, which are selected based on geographical location, such as school clusters in Singapore (Tan \& Ng, 2007), the cluster system (Thailand), Ruapehu Cluster (New Zealand), Pockets of Educational Excellence (United States) and Lancaster Schools Excellence Cluster in the United Kingdom (Noor Rezan, 2008). Instead of forming clusters around neighbouring schools, the Malaysian schools form clusters of excellence in niche areas (Mohd Noor \& Crossley, 2013). The selection process of such schools involves multiple stakeholders at the school, district, state and federal levels.

By 2015, the Ministry of Education Malaysia has recognised 506 schools as Cluster Schools of Excellence, making up five per cent of the total number of public primary and secondary schools in Malaysia (Azim, 2015). This meant that the MOE had exceeded its target of 500 cluster schools by 2015 (Azim, 2015). Since the programme was initiated in 2007, there had been nine phases of school selection. The ninth and final phase was implemented in 2015, hence the year 2015 was used as a benchmark in this study. After 2015, there were no additional CSE being announced.

The introduction of the CSE project in Malaysia was essentially a central decision, implemented at the micro-level. The initiative was aimed at granting selected schools and individuals more autonomy and responsibility (Nor, Hamzah \& Razak, 2019), which was important for the implementation of central goals. Malaysian Cluster Schools of Excellence are accorded autonomy in certain areas such as, among others, programme planning and financial management (Mohd Noor \& Crossley, 2013); which allow them to plan and implement micro-level initiatives while fulfilling macro-level education policy aspirations. This is in line with Shift Six of the Malaysia Education Blueprint (MOE 2013, p.259) to grant school authority greater autonomy over what happens in the classroom or the school.' To put things in perspective, the Malaysian CSE have flexibility in planning school-level programmes, however, these schools are still answerable to the central government and required to carry out programmes at the district and state levels.

\section{The Study}

The idea of having CSE as a form of decentralising education from the macro-level to the micro-level often results in varied dynamics in the implementation process, as exemplified in the decentralised centralism concept proposed by Karlsen (2000). This is perhaps because macro-policymakers are perceived to be unwilling to decentralise full autonomy; instead they tend to retain agency in certain areas directly or vicariously. This study attempts to explore how decentralised centralism fits in a Malaysian CSE framework and examines the dynamics and tensions involved in the decentralisation process. The study specifically considers whether a decentralisation process results in more 
decentralisation, centralisation or a blend of centralisation and decentralisation practices on the ground.

At the micro-level of the decentralisation process, it is vital to explore the school administrators as key agents as they are the ones who can drive major initiatives to achieve national aspirations. However, the literature is more focused on teacher agency (Hoppers, 1998) and learner agency in classroom practices (Ricento, 2006), it is still unclear as to what extent school administrators can exercise their autonomy in influencing policy decisions in the implementation process of a Cluster School of Excellence. This raises a pertinent question of whether autonomy and agency are held primarily by micro-level planners in a Cluster School of Excellence or invariably by the macropolicymakers instead. Taken together, the dynamics of the decentralisation process; the notions of autonomy and agency of school administrators as well as the macro-level government bodies, are discussed in relation to this study.

\section{Literature Review}

The literature on decentralisation of education is generally categorised into three strands. The first comprises the literature on full decentralisation; the second on decentralisation as a form of 'masked' recentralisation (Mifsud, 2016); and third, a decentralised-centralism strategy as a compromised position. The scholarly debate has often centred on the centralisation-decentralisation dichotomy, whether there needs to be more decentralisation, a tilt towards centralisation, or a balance of both spectrums.

According to Karlsen (2000), as a government strategy, decentralisation has been evident in Western societies and in developing countries (Rondinelli, 1983). Decentralisation and restructuring reforms give schools more power in decision making and have proven to impart a positive impact in improving school performance and effectiveness (Caldwell, 2005; Dykstra \& Kucita, 2008; Gamage, 2003). However, education transformation through decentralisation does not guarantee success and might not be sustainable (Bjork, 2006). Edwards and Mbatia (2013) argue that decentralisation reform is usually promoted without much consideration of its effectiveness, thus it is vital to understand how and why they work (or do not work) when putting theory into practice and why they are not successful in some circumstances.

According to Bjork (2006, p. 223), education decentralisation policies, although popular in Asia, have 'yielded an array of fascinating puzzles, lessons of experience, and unanswered questions.' One of the drawbacks of decentralisation has been its implications on widening disparity between urbanrural areas as shown in case studies in Singapore, Malaysia and Indonesia (Bjork, 2006), Korea (Jeong, Lee \& Cho, 2017) and China (Cheng, 1994), depending on the context and scale of its operation. Clearly, there is no one-size-fits-all solution across the vastly dissimilar developing countries. Phillips and Ochs (2003) argue the necessity for sustainable education reform and commitment to persist. These generate persistent curiosity and questions as to why decentralisation of education has not been as effective as some scholars have actively argued since the 1990s (Caldwell, 2005). The crux of the problem lies in the constant contestation of autonomy and agency among policymakers and policy implementers at the micro-level, hence the need for further understanding of the dynamics involved in the decentralisation process (Karlsen 2000).

\section{Centralisation versus Decentralisation of Education}

The 'centralisation-decentralisation axis,' coined by Isaac Kandel (1954), has dominated debates on paradigms of education reforms. On one hand, there is a need for monitoring and synchronisation of policies and practices by macro-policymakers; on the other hand, United Nations Educational, Scientific and Cultural Organisation (UNESCO), the World Bank and the Organisation for Economic, Co-operation and Development (OECD, 2015) widely acknowledge and advocate for decentralisation initiatives in developing nations. To a certain degree, decentralisation of education is considered 
a governance strategy that the state may employ to uphold its legitimacy, and to re-centralise its control over the schools (Karlsen, 2000). The process of decentralisation sometimes creates new forms of independent agencies or local authorities who act as proxies for the central authority; in other words, a form of 'masked' re-centralisation (Mifsud, 2016). In this context, decentralisation is often understood as a means to manage conflict and to give 'compensatory legitimisation' (Weiler, 1990). The federal government has to compensate 'the erosion of legitimacy', and decentralisation rhetoric is one strategy to strengthen its legitimacy and thereby maintain indirect power and control (Weiler, 1990).

However, Zajda and Gamage (2009) highlight the tension of balancing centralisation, which focuses on control and uniformity against decentralisation practices, usually associated with freedom, differentiation and responsiveness. For quality control purposes, centralised practices (UNESCO, 2005, p. 10-11) such as the league tables in Britain, US assessment under the No Child Left Behind legislation and French centralised curriculum could be justified. Contrastingly, strong opposition by the central government and government agencies, reluctant to relinquish their authority, are clearly exemplified in Pakistan and Singapore (Bjork, 2006). Bjork (2006, p. 227) finds that "few Asian states have traditionally expected local educators or community members to actively participate in the management of public institutions, thus local actors may be unprepared to respond to the reforms through decentralisation". Amidst the clashes between centralisation and decentralisation, Lockheed (1997) rules out the existence of a fully centralised or decentralised education system since all education structures make decisions at many institutional levels. Levin (1997, p. 260) succinctly points out that decentralisation represents a wide range of practices, 'some of which appear very little different than the supposedly more centralised approaches they have supplanted'. This strengthens the case that decentralisation as an education reform in one situation, can also be perceived as centralisation in another.

\section{Decentralised Centralism}

Karlsen (2000) proposes decentralised centralism as a politically adequate answer to present problems and government crises. The strategy compensates for the lack of legitimacy of the central authorities. However, there are various tensions and challenges in the implementation of the decentralised centralism strategy due to the contrasting, contradictory and ambiguous factors in the decentralisation process (Karlsen, 2000).

Karlsen's decentralised centralism illustrates the four dynamics in the decentralisation process. The first process is usually the dynamics of initiation, which refers to the practice where decentralisation reforms are initiated from the top by the authorities at the central level, but implementation and accountability are regarded as micro-level responsibilities. However, these reforms have often led to new central legislation and regulations, and can be a strategy for consolidating central locus of power (Tan \& Ng, 2007). Dynamics of content, which involves the disparities in curriculum and implementation practices in the decentralisation process, is not being emphasised in this study. The third process in the decentralisation process is the dynamics of levels. Decentralisation of tasks and administrative responsibility to the micro level does not necessarily result in a shift of power from a higher to a lower level (Tan \& Ng, 2007). The parallel nature of centralisation and decentralisation at work; and the management of the tensions that come with it, are vital concepts under the fourth decentralisation process: dynamics of simultaneity. The dynamics of simultaneity (Karlsen, 2000) is largely considered as an important element in decentralised centralism as it was a feasible approach to handle the persistent dilemmas within the macro-micro policy network, as shown in Karlsen (1999) and Levin \& Young (1994).

Inevitably, there will be constant transitions and reforms of education governance in most countries. "Some of these shifts will be centralising, others decentralising, and yet others will be both centralising and decentralising at the same time" (Bray 1999, p.228). Due to the mixed outcomes of the decentralisation policies, a balanced approach of centralisation and decentralisation appears to 
be the preferred model (Mundy \& Verger, 2015). The debate on when, what and how to decentralise will remain a contested territory in the education reform literature.

\section{Decentralisation and Agency of School Administrators}

The underlying concept of agency is inextricable when discussing the process of education decentralisation. Agency at the local level refers to the capacity of individuals to perform actions (Meyer \& Jepperson, 2002). School administrators' agency is increasingly crucial in school-level decision-making (Mintrop 2012; Rigby, Wouflin \& Marz, 2016). When autonomy is decentralised at the micro-level, school administrators have pivotal agency in policy implementation (Salter, 2014). In this context, the school administrators, i.e., the School Head and the Senior Assistants, have the agency to exercise autonomy in terms of planning and implementing policies in a CSE. The concepts of decentralisation of education through the formation of CSE, agency and autonomy at the local level; are interconnected within a complex macro-micro policy planning structure (Goggin et al., 1990; Ricento, 2006).

\section{Methodology}

In this study, the case study approach is adopted. A case study of this nature strives for a thorough understanding by drawing upon the agency and autonomy of key actors and the dynamics involved in the decentralisation process. Single cases provide glimpses into complex interplays between policies, pedagogic practices and institutional constraints (Ramanathan \& Morgan, 2007). This case study is aimed at fleshing out the nuances of key stakeholders within multiple institutional layers, such as the agencies in Ministry of Education and the Cluster School of Excellence, over a period of six months. The study presents findings from one particular CSE, elucidating a microcosm of the intricacies on how autonomy plays out and to what extent the school administrators exercise their agency. Only by studying micro-level policy implementation and its nexus with the macro-level aspirations, can we fully understand the true picture of the dynamics and tensions within the decentralisation process.

\section{Research Site}

The site chosen for this study is CS (a pseudonym), a national-type government primary school, situated in an urban, cosmopolitan area in Malaysia. CS has 60 teachers and about 1000 pupils. The school has a multi-racial make-up in terms of its teacher and student population. This national primary school was accorded its CSE status with English as its primary niche area and Robotics as a supporting niche area in Malaysia. CS is among the few Cluster Schools of Excellence with English as its primary niche area, thus this study focuses on its English niche area.

The participants selected in CS comprise the three school administrators which include the School Head (Chong, a pseudonym) and two Senior Assistants in Academic Affairs and Student affairs respectively (Lum and Ho, pseudonyms). The participants are chosen due to their considerable experience in the management of a Cluster School of Excellence. The school administrators are involved not only in the planning of school-level policies, but also form an integral part in driving the CSE policy implementation since 2010.

\section{Sources of Data}

Interviews with the School Head and the Senior Assistants form a major part of data collection. Interview transcriptions are largely used to provide a rich interpretation and thick descriptions (Geertz, 1973) of the reality on the ground. Official documents such as Request for Proposals, CSE Policy, the Treasury department guidelines (MOE, 2006) and the English Language Panel Report were used as references in this study. 'Request for Proposal' (RFP) is an official document required 
for CSE to get approvals for niche area's programmes and funding. The analyses provided a better understanding of how policies were manifested at the ministerial and school-levels as part of the multi-layered institutional onion (Ricento \& Hornberger, 1996).

\section{Trustworthiness of the Research and Ethical Considerations}

Trustworthiness of the research is an essential element to be considered in qualitative research studies. To ensure confidentiality of informants and to enhance trustworthiness of the findings, pseudonyms were used in this study. The name and exact location of the school would not be revealed in any part of my research to ensure privacy and confidentiality of the school authorities. To ensure credibility of the research, this study adopts a case study methodology, which is a wellestablished research methodology. Triangulation of data collection methods, in this case, interviews with school administrators and official documents, is employed to increase trustworthiness of the research findings.

\section{Findings}

To provide a comprehensive account of the complexities in a decentralisation process, it is crucial to explore the five main implementational aspects stipulated in the Malaysian CSE Policy (MOE, 2006), i.e.: the selection of niche areas, preparation of the Request for Proposal, financial management, advancing the niche areas, and exercising autonomy. The findings are arranged based on these five implementational aspects as each of these aspects is instrumental in ensuring the successful implementation of a CSE. Narratives of the five aspects and the dynamics involved in the decentralisation process are highlighted, especially in terms of the 'why', 'when', 'how' and 'who' exercise their agency as well as the implementational complexities at the ministerial and school levels.

\section{Selection of Niche Areas}

The first implementational aspect of the CSE Policy is the selection of niche areas. The selection of niche areas is a key aspect of autonomy which defines a CSE. The Ministry of Education Malaysia allows the school authorities in a CSE to propose its own niche areas, usually based on the expertise and potential of the school. The niche areas will then be finalised in writing by the Residential Schools and Excellent Schools Division (hereafter RSESD), a division under the Ministry of Education, tasked to facilitate the implementation process of the CSE at the ministerial level.

The selection of niche areas is an interesting case in point as school administrators typically have the agency in deciding their niche areas. As the School Head for more than ten years in CS, Chong stresses that it is pivotal to have "a group of teachers who share a common vision and mission to ensure the success and sustainability of school-level programmes". Thus, Lum, the Senior Assistant in charge of Student Affairs, states that there is a "mutual consensus among the school administrators and staff that English language would be their ideal niche area based on their track record in winning many national and international accolades" in recent times. Lum adds that the school authorities choose English language as their niche area as there are "many competitions in the world in English" that they can focus on. According to Lum, teachers and students in CS also "have more opportunities to participate in various English-based programmes at regional, national and international levels". Lum, for instance, was a leading figure in coaching students for choral speaking competitions. Since the school authorities have the resources and expertise in training choral speaking, storytelling, Scrabble and other English language programmes, CS would have a comparative advantage over other local primary schools by strategically choosing English language as their niche area. The study offers insights on how the school administrators utilise their agency in choosing a suitable niche area for CS. In a decentralised framework, the school administrators in 
CS have the autonomy to choose the niche areas they can excel in, so that they can perform their best and be a role model for other CSE.

\section{Request for Proposal}

The Request for Proposal (RFP) is usually the second stage of the implementation process. Before implementing any programme under the niche areas, the school authorities need to submit a formal Request for Proposal to RSESD. Lum has been a key master planner of the Request for Proposals (RFP) for the past four years ever since CS was accorded its Cluster School of Excellence status. From one point of view, MOE places the trust on CS to perform what they have envisioned to achieve in the RFP. The Senior Assistant, Lum, adds that "usually the ministry would not question much" on "where we [as a school] are, what we can do, what we can't do and what we have to do" when they present the RFPs. Ho, who has been the Senior Assistant 1 in charge of academic affairs in CS for the past five years, explains that "They usually approve the programmes as long as it is not political." However, the submission of the proposals is not a mere formality. Further responses by Lum demonstrate that procedures of preparing and submitting the RFP are not as clear-cut due to interference at the macro-level. Apart from being non-political, other issues for instance the budget, the hiring of coaches and the suppliers chosen can also be queried by RSESD in Putrajaya. Lum is quoted as saying:

Only when the programmes and budget are approved by the Ministry can the school proceed with the activities. Usually, the school is asked to alter its budget and answer some queries on the viability of the projects planned...All the proposals every year are different and with different requirements.

The school administrators are aware that without the Ministry's approval of the programmes and the budget, it is not possible to proceed with the implementation of the programmes. Lum further points out that, RSESD sometimes approve RFP "with conditions". Based on the findings, RSESD stipulates that the coach hired "should have a certificate and be registered with the government". The school administrators in CS need to exercise agency in the context of bureaucratic constraints, by selecting from their list of certified coaches for instance, in choral speaking and drama. The school administrators does work within the implementational spaces to achieve their objectives. The school administrators shared that these macro-micro implementational tensions (between the government agencies and the school authorities) eventually prolonged the procurement and subsequently the approval process.

The findings further revealed that though The Residential Schools and Excellent Schools Division (RSESD) under MOE provided guidelines and a framework for RFPs (MOE, 2006), RSESD's conditions frequently delayed and hampered the progress of the programmes planned. The school administrators in CS regarded the RFP procedures as a form of red tape, which was an extra burden to them. When faced with these issues, Lum posits that the school administrators adopt a pragmatic approach of not to "resubmit new RFP", but to "alter the proposal to fulfill the requirements for approval by the higher authorities". This study fleshes out "what" needs to be done in the preparation of RFP as well as "when", "how" and "why" RFP planning and approval are problematic. The nuances in the RFP planning and approval procedures highlight the prevalent tension that arises between the central authorities and local school administrators. The frequent contestation between centralisation and decentralisation has manifested itself in this context. As a government entity, RSESD plays the role of micro-managing CS to ensure accountability of the school administrators. The government is perceived to re-centralise the autonomy to a central division to oversee the programme planning and budget for CS. Here, the decentralised centralism strategy was demonstrated. The central 
agency (RSESD) retains the autonomy to approve RFPs even though micro-level policy actors at CS can exercise their agency in planning the RFP within a decentralised structure.

\section{Financial Management}

The school administrators in CS are accorded autonomy in managing the allocated funds for the niche area. However, the Treasury Circulars and Guidelines (MOE, 2006) needs to be adhered to by CS when planning budget allocations in their respective niche area(s). For the previous section on RFP, the central agency was concerned with the coaches hired by CS, however in this section on financial management, the ministerial entity pays particular attention on the suppliers for the programmes.

In terms of usage of funds, Lum was dissatisfied that the MOE was more concerned with "who [which suppliers] they get it from" with regards to food, books and costumes for choral speaking and English-in-Camp. Lum explained that the preferences and recommendations from the ministry are not always ideal as some suppliers were not "registered with the government". Lum argued that there was a mismatch when they compared prices with the suggested suppliers from the government who tended to offer higher prices than the initial proposed supplier, who happened to be unregistered. To resolve the macro-micro implementational tension, the school administrators resorted to "selecting suppliers from a limited pool of government-registered suppliers". This again disrupted their progress as the school authorities were required to defer the implementation of the programme and resubmit their Request for Proposal for approval. This analysis shows that the central agency has the final discretion in niche area funding approvals and that so-called macromicro discrepancies between CS and the ministerial entity tend to convolute financial management in CS. Thus in financial management, the Ministry of Education, via the Treasury Department, employs a decentralised centralism strategy as a governance mechanism for check and balance. Inevitably, however, occasional bottlenecks involving "mismatches" between federal authorities and school administrators are part of the unintended consequences (Hood, 2006) in education policy implementation.

\section{Advancing the Niche Area}

"Advancing the niche area" is generally viewed as expanding and extending the programmes by including a greater number of students; and introducing innovative practices to develop the niche areas. One of the flagship programmes stipulated under the CS niche area is "English-in-Camp". Using a case study approach, "when", "how" and "why" "English-in-Camp" programme is relevant to advancing the niche area are explored. The English-in-Camp programme is targeted for Level Two primary students, who are in Year Four, Year Five and Year Six. The English-in-Camp document states, "This camp is open to all Level Two primary students". At the micro-level, Lum explained that apart from the Level Two students, the school administrators tried to "include most Year Two and Year Three students [who are still at Level 1]." This is where CS authorities have the flexibility to involve more students provided "there is no additional budget implication." In this case, the school teachers and staff have the agency to tailor some of the activities to cater to the needs of Year Two and Year Three learners. This, in the view of the school authorities, was practical and impactful in advancing the niche area since a much bigger number of students can participate in a wide range of activities during English-in-Camp. The scenario reveals the agency of school-level decision makers in reinterpreting a specific section of the English-in-camp document, with the purpose of advancing the niche area. This is one of the available implementational spaces explored by micro-level actors.

\section{Exercising Autonomy}

School administrators are often regarded as anchors of school-level initiatives. This section demonstrates how school administrators exercise their agency in engaging with the parents and 
the Parent-Teacher Association members to help support school-level programmes. Chong, the School Head and the other school administrators, have been playing a "proactive role in courting the parents" to contribute to the school. According to Chong, they identify the "parents who attend Parents-Teachers Association meetings" and "those who are often present in school for various school functions and events". The following excerpt from the interview with Chong exemplify how and why parents are courted to assist in the school's programmes.

\begin{abstract}
I hope to pull in parents to help. Any parent will do. Because our hands are tied. The teachers need to do their core business. We use personal approach to get the parents to help. All of us ask the same questions. They (the parents) help on a voluntary basis, especially those with talents and experience. Some parents willingly co-train students for public speaking and choral speaking competitions. There is even a duty roster for parents to be the traffic guards during peak hours in school! A few volunteer to help with early morning reading with the students, while some others assist the remedial students improve their literacy skills.
\end{abstract}

Evidence from the interviews show that the school administrators, including Lum and Ho, "use personal approach to get the parents to help". Interestingly, the school administrators would "teach the other teachers to ask the same questions" to the parents identified, especially those with specific "talents and experience". The school authorities actively exercise their agency in courting the parents to assist in the school programmes. Chong and Lum feel that parental support "helps build a stronger camaraderie between the staff and the community and create a positive learning environment" in CS. This is a policy implementational space explored by the school administrators as there is no provision in the CSE Policy framework constraining them from recruiting parents to help in school programmes. The school administrators at the micro-level can exercise their autonomy innovatively to suit the needs of the school and community.

The analyses of the five implementational aspects revealed that the school administrators have agency to work within their implementational spaces in the "Selection of Niche Areas", "Advancing the Niche Areas" and "Exercising Autonomy" while the government still retains some control in "Request for Proposal" and "Financial Management" via RSESD and the Treasury Department.

\title{
Discussion
}

The findings illustrate the complex interplays between MOE and a Cluster School of Excellence. "The relationships within and between public agencies are highly complex and difficult to manage" (John 2012, p.21). Agency and autonomy exist at both macro (RSESD and Treasury Department) and micro-level (School administrators in CS). When appropriating the macro at a micro-level, agency is supposedly transferred to school administrators. However, as the data has shown, many of their plans require approvals by the macro-policymakers before implementation (MOE, 2006). The scenarios are linked to the complexities of translating policy into practice (Mohd Noor and Crossley, 2013) in multilayered bureaucracies. Notwithstanding such complexities in educational policy implementation, the agency of school administrators should not be viewed as largely insignificant as the findings illuminate that school administrators can exercise their agency within their implementational spaces in three of the five main implementational aspects of a Malaysian Cluster School framework. The agency and autonomy of policy actors at the macro-micro levels are also linked with the dynamics of decentralisation process (Karlsen, 2000) in a decentralised-centralism framework as discussed below.

\section{Dynamics of the Decentralisation Process}

While the analysis indicates that decentralisation of education system is strongly advocated in the Malaysian Education Blueprint (MOE, 2013), on the flipside, the terms and conditions in the CSE policy (Aziah, 2010) validates the MOE's perceived unwillingness to accord greater autonomy directly into the hands of the school administrators. Aziah (2010) cautions that whilst the CSE are encouraged 
to be more creative in introducing innovations to accelerate their organisational excellence and establish themselves as active learning organisations, these organisations are still guided by a set of standards. Inevitably, the aspirations of the macro-policy actors tend to offset the intentions of the micro-level agents.

Using the decentralised centralism strategy (Karlsen, 2000), the study has teased out the dynamics of the intricate decentralisation process within the Cluster School of Excellence structure. On one hand, the School Head and the Senior Assistants can exercise their autonomy to decide on the niche areas in CS. On the other hand, when it comes to the Request for Proposal and funding approvals, the school administrators are constantly in a quandary. They respond by framing RFPs according to specifications and guidelines which fit the criteria and ethos in CS. The RSESD and the Treasury Department at MOE, meanwhile play the role of approving or disapproving RFPs; or at times delaying the approval subject to fulfilment of prior conditions. One form of dynamics of the decentralisation process which is useful in explaining such phenomenon is the dynamics of levels. Each institutional level would exercise the agency they have, which results in frictions and delays in the implementation process. Consequently, there are bound to be tensions and conflicts related to budgetary decisions as exemplified in the findings.

Periodic monitoring is conducted by RSESD to ensure proper execution of niche area programmes and full compliance of the CSE policy guidelines. Herein lies the dilemma of responsiveness versus accountability among school administrators. MOE recognises the need to function as a check and balance tool to CS in terms of school-based management, i.e. financial planning, programme planning and procedural requirements. The school administrators normally attempt to fully oblige with the MOE's conditions, with the interest of school-level stakeholders in mind, as part of their administrative accountability. However, the macro-level intervention often causes bottlenecks and eventually interrupt the process. Dynamics of simultaneity (Karlsen, 2000) is elucidated in the analysis of the decentralisation process. There is a simultaneous practice of centralisation, as the central level sets clear goals and standards for outcomes; and decentralisation, where the means and the responsibility for implementation are local duties (Tan \& Ng, 2007). Such decentralisation dynamics illuminate the frequent contestations of agency and autonomy among the policy actors within the macro-micro framework.

One may argue that the school administrators are bound by the macro-policy framework; nevertheless they can work within the implementational spaces available as part of micro-level policy planning (Giddens, 1979; Sabatier, 1986). The school administrators can, to a certain extent, exercise their autonomy by reinterpreting policy documents. Dynamics of simultaneous practice of decentralisation with flexibility and autonomy for the schools, and centralisation with central goals and standards for the outcomes (Tan \& Ng, 2007); are often inevitable in a complex web of decentralised centralism spectrum. For instance, the English Camp programme, as stipulated in the policy document, was targeted for Level Two students. However, the School administrators, utilising their agency, involved Year Two and Year Three students as well. Lipsky (1980) argues that top-down policies tend to overlook, or underestimate, the tactics used by street-level bureaucrats to work within the policy implementation spaces according to their own self-interests. As street-level bureaucrats, the study has shown that school administrators, who are key policy actors, do exercise some agency (Doolan \& Blackmore, 2017) in influencing policy practices and processes at the school level. For instance, they exercised their autonomy in micro-level policy implementation by engaging with the Parent-Teacher Association members and parents to help in advancing the niche area.

\section{Decentralisation, Re-centralisation or Decentralised Centralism?}

Under the dynamics of initiation in the decentralisation process, decentralisation reforms are usually initiated from the top by the authorities at the central level (Karlsen, 2000) as can be seen in the 
CSE framework. The Malaysian Ministry of Education initiated the decentralised initiative; whilst implementation and accountability are considered micro-level responsibilities (Karlsen, 2000). Although CSE is part of the national education decentralisation initiative, the unplanned outcome of such policy planning (see Baldauf, 1994; Hood, 2006) is that autonomy and agency might be inadvertently re-centralised at the hands of the school administrators, as shown in the findings.

Depending on the context, what is considered 'decentralisation' at one level, can easily be seen as 'centralisation' at another (Karlsen, 2000). Re-centralisation at CS occurs when school administrators have substantial autonomy and agency to plan and conduct school programmes. School administrators, in this case, refer to the School Head and the Senior Assistants. The findings show that the school administrators decide on the niche area, have some form of agency in advancing their niche areas and exercise their autonomy in implementing school-based policies. Such observations are also in line with Karlsen's dynamics of levels and dynamics of simultaneity. In the decentralisation process, both centralisation and decentralisation at various levels of governance occur in varying degrees, which results in autonomy and agency being re-centralised at the local level, as highlighted in the findings.

The act of the decentralisation process via the establishment of CSE has caused the emergence of a tacit power base being re-centralised at the macro-level. RSESD and the Treasury Department have, intentionally or unintentionally, become entities with the potential of micro-managing (Smith, 2016) CSE; as these government agencies have the power to approve or reject Request for Proposals on the pretext of ensuring accountability of the school administrators. These agencies are also responsible for monitoring schools through on-site audits and scrutinising niche area reports. Paradoxically, decentralisation is countered by systematic regulatory re-centralisation (Edwards \& Mbatia, 2013; Lee, 2006; Tan \& Ng, 2007). One should ponder whether decentralising in this context, "masquerades" as a "masked recentralisation" (Mifsud, 2016). This leads us to question whether Malaysian Cluster Schools of Excellence are a form of decentralisation, re-centralisation or more accurately, a "decentralised-centralism" strategy (Karlsen, 2000). The form of decentralised-centralism strategy is more appropriate in this case, as the situation mirrors both a systematic regulatory recentralisation (Tan \& Ng, 2007) as well as perceived 'masked re-centralisation' (Mifsud, 2016) as part of the 'decentralising' process.

\section{The Way Forward}

To heed the clarion call for greater decentralisation of education, more autonomy should be given by macro-level agencies; in turn, there needs to be a proper check-and-balance (monitoring) mechanism that functions accordingly. Neither should be overlooked in the pursuit of greater decentralisation. Moving forward, the decentralised-centralism strategy is likely to be a compromised solution, or a so-called 'win-win' situation that satisfies the regulatory bodies at the macro-level besides allowing agentive spaces to be explored in the implementation of CSE.

\section{Conclusion}

The main argument driving this research is that school administrators can exercise their agency in education policy implementation at the micro-level albeit with some intervention from the federal government departments. The paper has problematised decentralisation of education at both the macro and micro-levels. The findings reveal that despite further autonomy accorded to the local school authorities, macro-level agencies do not completely relinquish control and continue to monitor the Cluster School of Excellence for accountability purposes. Fundamentally, the paper highlights the complexities and the implementational tensions involved in (i) the dynamics of the decentralisation process, where both the macro, and more importantly micro-level key actors exercise their agency and autonomy in varying degrees in different contexts of policy implementation; and ii) re-centralisation 
of authority through decentralisation, in other words, the acts of decentralisation result in hybrid forms of centralisation, as exemplified in the findings. Taken together, the decentralised centralism implementational dynamics in the Malaysian Cluster School of Excellence framework necessitates a nuanced reading of the nexus between the macro and micro education policy spheres.

\section{References}

Aziah, I. (2010). Accelerating Cluster School Excellence within Guided Autonomy Periphery: A Malaysian Case. Universiti Sains Malaysia, Pulau Pinang: Pusat Pengajian Ilmu Pendidikan[Centre for Education Knowledge].

Azim, I. (2015) MOE Exceeds Target of More Than 500 Cluster Schools By 2015. Available at https://www.nst.com.my/news/2015/09/moe-exceeds-target-more-500-cluster-schools2015[Accessed 28 February 2020]

Baldauf, R. B.(1994). 'Unplanned' language policy and planning. Annual Review of Applied Linguistics, (14), pp. 82-89. DOI:10.1017/S0267190500002828

Ball, S.(2012). Global Education Inc.: New Policy Networks and the Neoliberal Imaginary. Abingdon: Routledge.

Bandur, A.(2012). School-based management developments and partnership: Evidence from Indonesia. International Journal of Educational Development, 32(2), pp. 316-328.

Bjork, C.(2006). Conclusion: Connecting theory and practice in efforts to decentralise education systems in Asia. In C. Bjork (Ed.) Educational Decentralisation: Asian Experiences and Conceptual Contributions. The Netherlands: Springer, pp. 149- 158.

Bray, M.(1999). Control of education: Issues and tensions in centralisation and decentralisation. In R. F. Arnove \& C. A. Torres (Eds.) Comparative Education: The Dialectic of the Global and the Local. Lanham, M D: Rowman and Littlefield, pp. 207-232.

Caldwell, B. J.(2005). School-based Management. Paris/Brussels: IIEP/International Academy of Education.

Chapman, D., Barcikowski, E., Sowah, M. \& Gyamera, E.(2002). Do communities know best? Testing a premise of educational decentralisation: community members' perception of their local schools in Ghana. International Journal of Educational Development, 22(2), pp. 181-189.

Cheng K. M.(1994). The changing legitimacy in a decentralizing system: The state and education development in China. International Journal of Educational Development, 14(3), pp. 265-269.

Chikoko, V.(2009). Educational decentralisation in Zimbabwe and Malawi: A study of decisional location and process. International Journal of Educational Development, 29(3), pp. 201-211.

Cuéllar-Marchelli, H.(2003). Decentralisation and privatization of education in El Salvador: Assessing the experience. International Journal of Educational Development, 23(2), pp. 145-166.

Doolan, J. \& Blackmore, J.(2017). Principals talking back to mediatised education policies regarding school performance. Journal of Education Policy, 33(6), pp. 1-22.

Dykstra, A. H. \& Kucita, P.(2008). School-Based Management through Cluster Schools: A Case Study from Cambodia. Available at www.eric.ed.gov[Accessed 13 September 2018].

Edwards Jr., D. B. \& Mbatia, P.(2013). Education decentralisation and school clusters in Namibia: technical, institutional, and political dimensions. In A. Verger, H. Kosar-Altinyelken \& M. de Koning (Eds.) Global Managerial Education Reforms and Teachers: Emerging Policies, Controversies and Issues in Developing Contexts. Brussels: Education International, pp. 55-73.

Gamage, D.(2003). School-based Management Leads to Shared Responsibility and Quality in Education. A paper presented at 46th Conference of the CIES at New Orleans in USA in March 2003. Available at http://www.eric.ed.gov/PDFS/ED482345.pdf[Accessed 10 September 2018].

Gamage, D. T. \& Sooksomchitra, P.(2004). Institutionalisation of reforms involving decentralisation and school-based management: Thailand's experience. International Review of Education, 50(3-4), pp. 289-305. 
Gamage, D. T. \& Zajda, J.(2005). Decentralisation and school-based management: A comparative study of self-governing school models. Educational Practice and Theory, 27(2), pp. 35-58.

Geertz, C.(1973). The Interpretation of Cultures. New York: Basic Books, Inc.

Giddens, A.(1979). Central Problems in Social Theory: Action, Structure, and Contradiction in Social Analysis. Berkeley: University of California Press.

Goggin, M. L., Ann O'M. B., James P. L. \& Laurence J. O’Toole, Jr.(1990). Implementation Theory and Practice: Toward a Third Generation. Glenview, IL: Scott Foresman \& Co.

Hood, C.(2006). Gaming in target world: The targets approach to managing British public services. Public Administration Review. July/August, pp. 515-521.

Hoppers, W. H. M. L.(1998). Teachers' resource centres in Southern Africa: An investigation into local autonomy and educational change. International Journal of Educational Development,18(3), pp. 229-246.

Hornberger, N. H. \& Johnson, D. C.(2007). Slicing the onion ethnographically: Layers and spaces in multilingual language education policy and practice. TESOL Quarterly, 41, pp. 509-532.

Jeong, D. W., Lee, H. J. \& Cho, S. K.(2017). Education decentralisation, school resources, and student outcomes in Korea. International Journal of Educational Development, 53(2), pp. 12-27.

John, P.(2012). Analysing Public Policy. New York: Routhledge.

Kandel, I.(1954). The New Era in Education. London: George Harrap.

Karlsen, G. E. (1999). 'Decentralised-centralism' governance in education: Evidence from Norway and British Columbia, Canada. Canadian Journal of Educational Administration and Policy, 13, pp.1-15.

Karlsen, G. E.(2000). Decentralised centralism: framework for a better understanding of governance in the field of education, Journal of Education Policy, 15(5), pp. 525-538.

Khanal, P.(2010). School decentralisation in Nepal: A disjuncture between macro-level advocacy and micro-level reality? Educational Research for Policy and Practice, 9(3), pp. 145-158.

Lee, M. N. N.(2006). Centralised decentralisation in Malaysian education. In C. Bjork (Ed.) Educational decentralisation: Asian Experiences and Conceptual Contributions. The Netherlands: Springer, pp. 149- 158.

Lefebvre, E. E. \& Thomas, M. A. M.(2017). 'Shit shows' or 'like-minded schools': charter schools and the neoliberal logic of Teach for America. Journal of Education Policy, 32(3), pp. 357-371.

Levin, B.(1997). The lessons of international education reform. Journal of Education Policy, 12(4), pp. 253-266.

Levin, B. \& Young, J.(1994). Understanding Canadian Schools. An Introduction to Educational Administration. Toronto: Harcourt Brace \& Company.

Lipsky M.(1980). Street-Level Bureaucracy: Dilemmas of the Individual in Public Services. New York: Russell Sage Foundation.

Lockheed, M.(1997). Decentralisation of Education: Eight Lessons for Social Effectiveness and Improvement. (Power point presentation). Available at www1.worldbank.org/education/global/ educationreform/ppt/m.lockheed.ppt.[Accessed 10 June 2018]

M'Nkanata, K.(2012). Factors Affecting Effective Decentralisation and Management of Education in Abothuguchi West Division, Meru County, Kenya. Unpublished Masters Dissertation, Kenyatta University, Kenya.

Meyer, J. W. \& Jepperson, R. L.(2002). The 'Actors' of modern society: The cultural construction of social agency. Sociological Theory, 18(1), pp. 100-120.

Mifsud, D.(2016). 'Decentralised' neoliberalism and/or 'masked' re-centralisation? The policy to practice trajectory of Maltese school reform through the lens of neoliberalism and Foucault. Journal of Education Policy, 31(4), pp. 443-465, DOI: 10.1080/02680939.2015.1121409

Ministry of Education (MOE) (2006). Pelan Induk Pembangunan Pendidikan 2006-2010 [Education Development Master Plan 2006-2010]. Putrajaya: Ministry of Education Malaysia.

Ministry of Education (MOE).(2013). Malaysia Education Blueprint (2013-2025). Putrajaya: Ministry of Education Malaysia. 
Mintrop, H.(2012). Bridging accountability obligations, professional values and (perceived) student needs with integrity. Journal of Educational Administration, 50(5), pp. 695-726.

Mohd Noor M.A. \& Crossley, M.(2013). Educational innovation and the knowledge society: development and issues of the clusters of excellence initiative in Malaysia. Asia Pacific Journal of Education, 33(2), pp. 156-169.

Mundy, K. \& Verger, A.(2015). The World Bank and the global governance of education in a changing world order. International Journal of Educational Development, 40, pp. 9-18.

Niño-Zarazúa, M.(2016). Aid, education policy, and development. International Journal of Educational Development, 48(3), pp. 1-8.

Noor Rezan, B. H.(2008). Sekolah Kluster: Kejayaan dan Cabaran. [Cluster schools: Successes and Challenges]. Deputy Director General of Education's speech presented at the Second National Convention on EDMP 2006- 2010 at Institute Aminuddin Baki, Malaysia 24 - 27 November.

Nor, M. S. M., Hamzah, M. I. \& Razak, K. A.(2019). Cluster schools of excellence: Concept and implementation. International Journal of Academic Research in Progressive Education and Development, 8(3), pp.118-125.

OECD (2015). Education Policy Outlook 2015: Making Reforms Happen. Paris: OECD Publishing.

Parry, T. R.(1997). Achieving balance in decentralisation: A case study of education decentralisation in Chile. World Development, 25(2), pp. 211-225.

Phillips, D. \& Ochs, K.(2003). Processes of policy borrowing in education: Some explanatory and analytical devices. Comparative Education, 39(4), pp. 451-461. http://dx.doi.org/10.1080/0 305006032000162020

Ramanathan, V. \& Morgan, B.(2007). TESOL and policy enactments: Perspectives from practice. TESOL Quarterly, 41(3), pp. 447-463.

Ricento, T.(2006). An Introduction to Language Policy. Malden, MA: Blackwell.

Ricento, T. K. \& Hornberger, N. H.(1996). Unpeeling the onion: Language planning and policy and the ELT professional, TESOL Quarterly, 30(3), pp. 401-427.

Rigby, J. G., Wouflin, S. L. \& Marz, M.(2016). Understanding how structure and agency influence education policy implementation and organisational change. American Journal of Education, 122(3), pp. 295-302.

Rondinelli, D. A.(1983). Implementing decentralisation programmes in Asia: A comparative analysis, Public Administration and Development, 3(3), pp. 180-207.

Sabatier, P. A.(1986). Top-down and bottom-up approaches to implementation research: a critical analysis and suggested synthesis. Journal of Public Policy, 6(1), pp. 21-48.

Salter, P.(2014). Knowing Asia: creative policy translation in an Australian school setting. Journal of Education Policy, 29(2), pp. 145-164.

Smith, T.(2016). States Can Help Every Student Succeed. Available at https://www.usnews.com/ opinion/articles/2016-09-15/education-dept-is-micro-managing-the-every-student-succeedsact[Accessed 1 September 2018]

Tan, Y. S.(2012). Democratisation of secondary education in Malaysia: Emerging problems and challenges of educational reform. International Journal of Educational Development, 32(1), pp. 53-64.

Tan, C. \& Ng, P. T.(2007). Dynamics of change: The decentralised centralism of education in Singapore. Journal of Educational Change, 8(2), pp. 155-168.

UNESCO .(2005). Decentralisation in education: National Policies and Practices. Paris: UNESCO.

United Nations.(2015). United Nations Sustainable Development Goals (2015). Available at http:// www.un.org/sustainabledevelopment/sustainable-development-goals/[Accessed 1 December 2018]

Weiler, H. N.(1990). Decentralisation in Educational Governance: An Exercise in Contradiction? In M. Granheim, M. Kogan \& U. P. Lundgren (Eds.). Evaluation as policymaking. Introduction Evaluation into a National Decentralised Educational System. London: Jessica Kingsley. 
Decentralised Centralism: Insights from a Malaysian Cluster School of Excellence

World Bank.(2013). Malaysia Economic Monitor. High-Performing Education. Bangkok: World Bank. Zajda, J. and Gamage, D.(2009). Decentralisation, School-Based Management, and Quality Dordrecht: Springer. 
